\title{
Author Correction: Stretchable, dynamic covalent polymers for soft, long-lived bioresorbable electronic stimulators designed to facilitate neuromuscular regeneration
}

Yeon Sik Choi (1), Yuan-Yu Hsueh (1), Jahyun Koo, Quansan Yang (1), Raudel Avila, Buwei Hu, Zhaoqian Xie (D), Geumbee Lee, Zheng Ning, Claire Liu (D), Yameng Xu, Young Joong Lee, Weikang Zhao, Jun Fang, Yujun Deng, Seung Min Lee, Abraham Vázquez-Guardado (D), Iwona Stepien, Ying Yan, Joseph W. Song, Chad Haney (D), Yong Suk Oh (D), Wentai Liu, Hong-Joon Yoon, Anthony Banks, Matthew R. MacEwan, Guillermo A. Ameer,

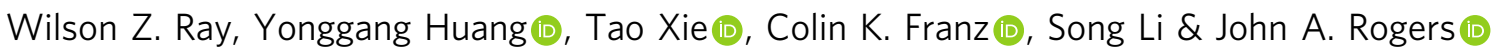

Correction to: Nature Communications https:/doi.org/10.1038/s41467-020-19660-6, published online 25 November 2020

The original version of this Article contained an error in the spelling of the author Hong-Joon Yoon, which was incorrectly given as Hong-Joon Yun. This has now been corrected in both the PDF and HTML versions of the Article.

Published online: 12 January 2021

\footnotetext{
(c) Open Access This article is licensed under a Creative Commons Attribution 4.0 International License, which permits use, sharing, adaptation, distribution and reproduction in any medium or format, as long as you give appropriate credit to the original author(s) and the source, provide a link to the Creative Commons license, and indicate if changes were made. The images or other third party material in this article are included in the article's Creative Commons license, unless indicated otherwise in a credit line to the material. If material is not included in the article's Creative Commons license and your intended use is not permitted by statutory regulation or exceeds the permitted use, you will need to obtain permission directly from the copyright holder. To view a copy of this license, visit http://creativecommons.org/licenses/by/4.0/.
}

(c) The Author(s) 2021 